Journal of Social Sciences 6 (1): 93-98, 2010

ISSN 1549-3652

(C) 2010 Science Publications

\title{
The Dissolution of the National Partnership for Excellence and Accountability in Teaching
}

\author{
Frank B. Murray \\ Department of Psychology, School of Education, Suite 101 Willard Hall Education Building, \\ University of Delaware, Newark, Delaware, 19716
}

\begin{abstract}
Problem statement: A heralded federal imitative known as The National Partnership of Excellence in Education (NPEAT), dissolved shortly after being formed. An analysis of some causes of the unexpected dissolution of NPEAT focuses on six causes (1) compromises in the initial competition for the partnership, (2) the funding mechanism as grant or contract, (3) the behavioral trap of sunk costs, (4) the confirmation bias over the NCTAF agenda, (5) confusion over mission as implementation or inquiry and (6) the nature of a partnership itself. Conclusion: Lessons for the invention of future national partnerships for the reform of teaching are discussed such as No child left behind or Race to the top.
\end{abstract}

Key words: Educational reform, educational policy, decision-making

\section{INTRODUCTION}

The National Partnership for Excellence and Accountability in Teaching (NPEAT), funded at \$23million by the Office of Educational Research and Improvement (OERI), was undertaken in 1997 with the promise that it would ensure the implementation of an educational reform agenda set out earlier by a leading group of scholars and policy-makers that called itself the National Commission on Teaching for America's Future (NCTAF). The partnership, however, was abandoned, unnoticed and without comment, less than two years later and well before the allocated funds were expended.

The puzzling demise of the partnership can be attributed to at least six factors, some embedded in the partnership's flawed initial design and all containing lessons for other national educational reform initiatives.

It is fair to say that NPEAT was never an unqualified success during its short years of operation despite the intrinsic merits of many of the 39 projects it undertook, the acknowledged eminence of its principal investigators and the substantial and disproportionate commitment of resources made to it by the Office of Educational Research and Improvement (OERI) of the US Department of Education. There were, of course, some bright spots in NPEAT's accomplishments-even in its first eighteen months-but nevertheless NPEAT was forced almost immediately to revisit its design (Bradley, 1999a) and make substantial changes in each in order to have continued support from OERI (Bradley, 1999b).

The Partnership, from its beginning in the Fall of 1997, was managed by a small group of Principal Investigators, known as The Management Committee, who had written and conceptualized the winning response to the Department of Education's Broad Agency Announcement (BAA). This announcement called for the development ofa new national partnership to study and implement the recommendations of the National Commission on Teaching for America's Future (NCTAF), which had issued its own report, What Matters Most, the year before. NPEAT responded to the NCTAF recommendations with 39 projects of its own, each coordinated and led by one or more of the PIs and organized as five inter-related $R$ and $D$ programs: (1) standards and assessments, (2) teacher education and professional development, (3) recruitment, (4) restructuring schools as learning organizations and (5) partnership development.

By 1999 the NPEAT projects were reconceptualized with the result that 17 projects were eliminated, half of the remaining 22 were substantially modified and the five programs were abandoned and replaced by three strands, as they were called-1., Teacher Preparation and Recruitment, 2., Professional Development and 3., Standards and Assessments. The Management Committee was also eliminated and replaced by the Policy Board, initially a peripheral advisory body that had not met in the first year. For all intents and purposes thereafter the Policy Board became NPEAT. Why were these costly changes 
required and what lessons are there for the continued work of other nationally inspired reform initiatives?

There are two overarching principles that place human decision-making and judgment at risk and both were implicated in NPEAT's formation. Each is well documented and a common feature of ordinary reasoning and each played a role that weakened the NPEAT initiatives and contributed to the need for redesign (Plous, 1993). There are also six general and inter-related factors embedded in these principles that operated in specific aspects of NPEAT's formation and execution.

The first principle is the behavioral trap of sunk costs as it is often called in the literature on human decision-making and reasoning. It played an extraordinary role in the formation of NPEAT within OERI and within the expanding set of NPEAT proposal-writers. Nearly all signs that the partnership could not work as intended were ignored in the face of each party's prior investments. The classic sunk cost effects occur when prior expenditures of time, money and other resources lead people to make choices they would not otherwise make. In a bidding game for one dollar, for example, where the top two bidders must pay their bid, even though only one wins the dollar, bidders will bid irrationally much more than a dollar for a dollar, a decision they would never make were they not invested in their bids. Such was the case in OERI and NPEAT because the prior investments OERI and the NPEAT proposers made in NPEAT clouded the clarity of their subsequent decisions (to some extent toward the end of NPEAT both OERI and NPEAT employed classic techniques to minimize harmful sunk cost effects by having the people who made the initial decisions not make the subsequent decisions. Both NPEAT and OERI at the end put had put new leaders and decision-makers into place).

The second overarching principle was the confirmation bias and it speaks to the intellectual heart of NPEAT and it was equally distorting. The confirmation bias is the tendency to attempt to prove an hypothesis through confirmation rather than through falsification or disconfirmation. More about this flaw in NPEAT's design and operation later, but generally it operates to mislead investigators about the truth of the situation by promoting self-fulfilling prophecies. It can be briefly illustrated as follows: Suppose the rule that generated the following three numbers, 2, 4, 6, is to be discovered. The rule seems obvious-the numbers are incremented by two. There is a strong and likely tendency to test this hypothesis with other sequences like, $8,10,12$, then $14,16,18$ and then perhaps 20, 22, 24. If positive results are secured from each test, the rule "increments of two from any starting number" is announced confidently as the solution to the problem. However, the rule in fact was "three numbers of increasing magnitude," which could have been determined had sequences that disconfirmed the " +2 " hypothesis (e.g., by trying 4-6,) been tried. Thus, a wrong conclusion was reached, stemming from efforts to only confirm, not disconfirm, the initial hunch.

The six factors implicated in the dissolution of NPEAT are inter-related and some are consequences of the others.

The open competition factor: OERI, presumably and naturally, thought the classic and tested benefits of a free and open competition were important and worth introducing into the formation of NPEAT. There is a widely accepted view that the best ideas and solutions bubble up when the net for them is broadly cast and all competent parties have an equal opportunity to contribute to the solution. Two crippling problems, however, occurred in the case of NPEAT.

The first stemmed from the fact that large segments of the winning proposal were put in place at least four months before the Broad Agency Announcement was made public. Thus, the true benefits of competition were lost as several potential solutions for a national partnership were discouraged by the presumed fait accompli of the winning group. Perhaps more damaging, the winning group had to conduct much of its early work in secret and on a confidential basis, thus depriving it of needed critical review and analysis-even within the proposed member organizations of the new partnership.

Apart from the unhealthy collusion that permeated the competition, there was a second problem and this was whether a partnership should have been, or even could have been, constructed on the basis of a competition. There are, after all, only so many natural partners out of which the envisioned national educational partnership could have been constructed. Some, by virtue of their centrality in the teaching profession, cannot be left out so they would have had to participate somehow in several different competing proposals and the competition would be hopelessly compromised at that stage. Thus, there was a conceptual flaw at the outset and it was embedded in the very notion of a competition, a competition that could not truly occur within and among a set of organizations that had to be part of any legitimate national partnership.

There are two lessons here-the normal competition, an axiom of federal awards, may not always be the most productive or sensible vehicle for an NPEAT 
venture, but if it is employed, then it must be properly executed. And this leads to the consideration of a second problematic factor in the NPEAT initiative.

The time for reflection factor: The time interval between the formal announcement and the submission deadline was, on any theory, too short for the kind of careful analysis that was needed, let alone the kind of political discussions that would also be needed to craft a true national partnership. As it was, even with at least four months additional time, the winning proposers spent very little time on the conceptual issues of their proposal. Their time was spent and really had to be spent, on (1) building a coalition of university researchers and key DC based organization representatives and (2) on the allocation of the funds and the research tasks. The records of the PI meetings, during the proposal development phase and budget renegotiation phase, indicate that substantive matters of logic, philosophy and fundamental contribution were invariably set aside in the face of more pragmatic matters of funding, proposal prose, strategy, effort reporting requirements and the wishes and demands of some influential PIs and partners.

This short time period for the actual writing of the proposal and for the building of a fragile coalition meant that some issues could not be resolved. Thus, NPEAT began without a coherent agenda or an accepted theory of action to guide its work. It, in fact, had within it at least two competing views of what it was to be (discussed below), but apart from that there was no time for the full discussion among the 39 project leaders to determine how each related to the others. It was well into the first year before the full group of PIs even met each other to discover what each was proposing to do or had initiated.

It was not the case that this problem went unrecognized, but that the time lines and financial constraints did not allow the kind of consistent and penetrating discussion all acknowledged needed to take place. This meant that the five initial programs were not really entities of any kind as no time could be given to building them and crafting a point of view and scope of integrated work for each and by each. NPEAT in fact could never get past the fact that it was little more than 39 separate projects.

More problematic and stemming from the same lack of time for reflection and analysis, was the fact that the partnering organizations had even less time to grapple with what it would mean for them to form a partnership to accomplish the NCTAF agenda. At best, each thought NPEAT was a way for each partner organization to accomplish some purpose of its own.
There was no evidence that any of them thought they had agreed to a venture that might require them to change some goal or aspect of their own work. This willingness to change one's own work is, of course, a precondition of any partnership and it requires considerable time to develop and explore new goals and accommodations.

A rational plan for the induction of new teachers into the profession, to take an example that each partner organization accepted as a genuine problem, would require modifications in (1) the school of education's advanced programs and post-graduate commitments, (2) the negotiated collective bargaining agreements between school boards and teacher unions about transfer and bumping rights, (3) the state funding formulas for mentors, interns and schools of education (4) the state's license requirements for initial and senior teachers, (5) school board and district policy about mentors, interns, professional development and seniority, , (6) accreditation standards that held schools of education accountable beyond the degree program and so forth. The nature of such mutually supportive changes requires intense discussion and consultation and no provision for this was made, or could be made, in NPEAT as it was designed and in the deliverable schedule approved and required by OERI.

The lesson is obvious and related to the sunk cost trap-the time needed must be allocated and fundamental issues resolved before the work is so compromised that it cannot succeed. One fundamental issue, the core of another ultimately unresolved problem, was the status of the NCTAF agenda itself.

The status of the NCTAF agenda factor: The relationship between the NCTAF and the NPEAT agendas was a perplexing issue. The confusion, resided in the coexistence of two competing NPEAT goals--(1) the study of the NCTAF agenda and (2) the implementation of the NCTAF agenda. NPEAT was to do research and wanted to do research, about the NCTAF agenda, but apparently only to confirm it, so that it could be implemented. This led to a strange kind of research in which parties with vested interests were researching the value of their own organization's contributions to the overall NCTAF goal of providing a competent, qualified and caring teacher for every child in the nation's schools. The National Board for Professional Teaching Standards (NBPTS), the National Council for the Accreditation of Teacher Education (NCATE), the American Association of Colleges of Teacher Education (AACTE), NCREST/INTASC, the Holmes Partnership, for example, all had a hand in determining the validity and 
value of their own organization's work for the national partnership. This kind of contamination of researcher and advocate would not stand scrutiny ultimately and ordinarily would make no sense as it violates many research canons. But it made a kind of sense if the point of NPEAT were to simply confirm the NCTAF propositions and to devise ways to support the propositions rather than test them. It also meant that little effort was made to falsify the NCTAF propositions, to disconfirm them and thus an essential ingredient in scientific and intellectual advancement was sometimes bypassed.

NCTAF's recommendations were after all only a set of hypotheses about how the nation should proceed to meet high standards. The hypothesis, announced as propositions by NCATF, was that the NBPTS, INTASC and NCATE standards were what mattered most for improving the nation's schools and they should be required and aligned with each other. It remained an open question whether NPEAT's role was to test this hypothesis, or simply assume it was true and move toward the research that would be needed to implement it. There would always be profound dissatisfaction on the part of those-within and outside NPEAT and OERI -- who thought NPEAT's role was one and not the other. Thus, NPEAT had within its community of researchers and partners a lurking tension about the fundamental status of NCTAF. It remained unresolved partly for the reasons other fundamental issues were unsettled in the first months of NPEAT. But it was not entirely over the lack of time, because the confusion also originated in OERI's own ambivalence about the status of the NCTAF propositions and whether NPEAT should genuinely subject them to scientific scrutiny or move on to their policy implementation.

The lessons here are of two sorts-it is wise to settle fundamental questions early in the enterprise and it is wise to avoid the intellectual error of seeking only confirmation when the rewards from disconfirmation efforts are richer and more lasting.

The contract mechanism factor: The fact that OERI employed a contract mechanism is consistent with the view that NPEAT's purpose was to confirm the NCTAF propositions because the contract presumes that someone actually knows beforehand what the products should look like. This would be the only basis upon which the specifications for the products could be written and their delivery engineered. However, it was abundantly clear that no one knew beforehand the specifications for the NPEAT outcomes and thus the contract mechanism was seen quite early on to be ill suited to everyone's purposes. Even so, following the sunk cost trap of other aspects of NPEAT, the contract mechanism dominated and distorted NPEAT's work.

The distortion occurred because the deliverable schedule was unforgiving and did not permit PIs to capitalize on new developments in their work and the fruits of other's work. Moreover, it forced premature decisions about the work that limited the work's potential. Consequently, NPEAT's few accomplishments were below the standard we usually find in creative work that isn't over until the solution is found. The contract regime wasted time, because time had to be devoted to deliverables that were merely the means to larger ends. Valuable time was spend making a polished and reimbursable deliverable out of a research design that inevitably had to change, or making a deliverable out of a limited literature search that subsequently had to updated and extended. Much time was wasted in evaluating products, or preproducts, that were merely means to larger ends and had no other point than being a deliverable that would authorize a funding stream. The entire contract mechanism assumed a predetermined linear progression of thought. Such neat progressions rarely characterize scholarly activity and development at the "cutting edge." The logic of discovery is understood to be different from the logic of justification, the latter being more amenable to a linear predetermined sequence of the story that follows the discovery, not precedes it. The NPEAT researchers clearly saw themselves and properly so, in a logic of discovery mode and were simply frustrated and unable to comply with the need to make substantial investments in inconsequential deliverables (even though they had agreed to do exactly that). So, by and large, they didn't submit their deliverables on schedule.

Apart from the poor fit between the demands of the NPEAT work and the requirements of a contract funding mechanism, there were serious implementation problems with the management and logic of the contract mechanism, largely on the part of OERI whose own interests were also not well-served by the predetermined linearity of what it had agreed to. The understandable efforts on OERI's part to amend the scopes of work, add new deliverables outside the agreed upon schedule, improve the work, respond to new national priorities were also signs that the contract mechanism had failed-yet it persisted as another sunk cost.

The lesson, almost too obvious to state, is that when all parties come to see that they have employed an inappropriate mechanism, a mechanism that is so flawed for the purposes to which it is being put, the mechanism should be changed. And if it cannot be 
changed, the mistake should not be repeated or perpetuated.

The factor of implementation or inquiry: The NCTAF propositions were not in fact given much attention in the design of NPEAT other than as an "invisible hand," or general guide, that eliminated competing policy initiatives like alternate routes to certification, vouchers, Teach for America, charter schools, alternative accreditation approaches, like TEAC, or unregulated private school achievement. While the fact of NCTAF played a key role in whether NPEAT's point was confirmation, the principal issue that remained unresolved and a source of tension within NPEAT (and between NPEAT and OERI) was whether NPEAT was fundamentally about (1) building and designing an enduring national partnership, (2) being that partnership, or (3) a research undertaking on questions raised in some way by NCTAF's recommendations.

Education policy in the US is generally grounded on political consensus and the wishes of powerful constituent groups. NPEAT, on one view, was about grounding education policy in research findings rather than on this well-meaning political consensus. Thus, NPEAT would provide a common ground where contentious political issues, like social promotion or class size, could be evaluated, grounded in solid research and settled once and for all. This was the value-added of the NPEAT agenda. The policy community would finally have authoritative evidence for its policies, particularly the policies recommended by NCTAF. This was what $\$ 23$ million was to purchase-or at least a promising beginning to that end.

Two problems were apparent in this view-one, it would take more time than the NPEAT funding cycle permitted to add this value and second, it was not clear what the organization members of the partnership would do with research results that challenged their own agendas (e.g., how could AACTE deal with a potential research result that showed no particular value-added benefit of university-based teacher education, the core activity of its members, or how could NBPTS deal with a potential finding that the students of NBPTS teachers were not superior to students of non-NBPTS teachers, or NCATE with findings that graduates from accredited education schools were less competent than graduates of unaccredited education schools, or even from those few schools denied accreditation by NCATE). Neither of these problems was fully addressed although much of the NPEAT work proceeded as if these were not problems-perhaps because confirmation was so confidently expected.

On another view, not necessarily incompatible with the first view, NPEAT was about building a national partnership of stakeholders in the NCTAF agenda who would use NPEAT as common ground on which to negotiate the changes each would have to make in its own operations so that the NCTAF agenda and goals could be accomplished. Whether NPEAT was that partnership, or simply the means of building that partnership, was unresolved, but it was clear that very little of the early NPEAT investment was directed at the construction of a genuine partnership of stakeholders. The organization, for example, was not able to find the time to debate or approve any bylaws for itself, nor did it convene the partner organizations or stakeholders for the purpose of building an organization, both of which might be seen as preconditions for building a partnership.

The view that NPEAT was about building a partnership was complicated by the fact that this was also the view of the Holmes Partnership, one of the NPEAT partner organizations, but a latecomer to the coalition that wrote the winning proposal. In fact, the Holmes Partnership was a potential and declared competitor for the NPEAT award before it joined with the winning coalition. In a sense, the original coalition held the view that NPEAT was primarily an R and D effort, while the Holmes "interlopers" held the view that NPEAT was primarily about building a partnership. The OERI staff seemed also to hold the partnership view but expressed it covertly through their dissatisfaction with the sometimes parochial and narrow NPEAT research agenda.

With the policy board replacing the management committee and becoming NPEAT in 1999, so to speak, it seemed that the partnership view of NPEAT had prevailed, but this would be in name only. It remained unclear how deep the commitments of the partner organizations were-rarely did the most senior representatives of the partner organizations participate in NPEAT meetings as they had in other key forums, for example. There was no evidence that any of the partners was willing to discuss modifications in cherished policies if such were found to be necessary to achieve the NCTAF goals. The critical and defining conditions for a genuine partnership, versus a collaborative or cooperative, were not met by the "partners" so it remained unclear whether the building of a lasting partnership to ensure that each American student has a caring, qualified, competent teacher was what NPEAT actually meant to do. 
The lesson, like those before, is that these alternative views of NPEAT needed to be reconciled and that it was unlikely that "business as usual" or "business as revised" would effect the resolution.

The transparency and authenticity factor: One aspect of leadership is that leaders act as they expect their followers to act. NPEAT accepted a national leadership role in which it would, at some point, ask large segments of the teaching profession to remove barriers to progress and implement some researchedbased policy recommendations. Its moral authority, if you will, to command the respect needed to motivate its partners to make these changes would be severely weakened if it could not remove the barriers (cited above) to its own progress. None of these issues was unknown to NPEAT and OERI and all were understood to be barriers to the goals NPEAT hopes to achieve. Yet everyone acted as if nothing could be done about themthe contract could not be converted to a grant mechanism, time limits were unmodifiable, the funds were only available at this moment, origins could not be revisited, rules could not be changed and so forth-and so the trap of sunk costs grew deeper.

The lesson is that NPEAT, if it was to be a partnership or even a catalyst for a partnership, also had to be what it would ask others to be. As part of that lesson, there was the fact that NPEAT did not actually manage its business very well. There were long delays in payments for approved deliverables, the approval of deliverables by OERI was equally slow and the submissions by PIs were often late. The PIs maintained schedules at variance with NPEAT's and OERI's and in the service of their other scholarly and professional commitments. Almost all the PIs gave only small percentages of their time to NPEAT. NPEAT was hardly any one senior person's full-time commitment, another weakness in the plan that was noted by OERI at the outset and passed over.

Finally, NPEAT needed to embody the very values of openness, free inquiry, scholarship and discipline it advocated if it were to craft solutions that would satisfy the diversity of problems and interests in American education. Here the politics of confirmation and the political interests of the influential, unduly constrained the NPEAT agenda by prematurely ruling out potential solutions that were not specifically mentioned or sanctioned in the NCTAF report. It also introduced an unwarranted and risky urgency into the work because authoritative answers were needed quickly to support some of the partners' own fast moving and threatened, political agendas.

\section{CONCLUSION}

A final word: The question naturally arises whether these factors, once evident, could have been attended to earlier and perhaps have helped NPEAT avoid the disruptive and costly redesign efforts it was forced to undertake and to stave off its premature ending. From the review of the record, the NPEAT organization was, quite understandably, driven by the need to win the OERI competition and thereafter to trim the activities to ensure that funding would be continued. These needs, following the logic of a Maslow hierarchy, simply drove out, or pre-empted, the higher levels of activity that would have been needed to absorb and respond to the problematic factors described above. Once again, this is not to say that there were not some bright spots in NPEAT's accomplishments-even in its short life. Many of the NPEAT investigators never lost their way with regard to these six factors and their projects will be seen as lasting contributions to the field. It is only to say that there are lessons to be learned in the formation of this once promising partnership that would apply equally to those who would seek to implement a nonNCTAF reform and renewal agenda for schools that leave no child behind.

\section{ACKNOWLEDGEMENT}

Primary funding for NPEAT came from the Office of Educational Research and Improvement, US Department of Education, under contract number RD97124001. The opinions expressed herein do not necessarily reflect the positions or policies of the Office of Educational Research and Improvement or the US Department of Education. A version of the article was in fact requested by NPEAT and OERI as a final deliverable of NPEAT Project 5.1.

\section{REFERENCES}

Bradley, A., 1999a. Teaching partnership regroups to define mission and survive. Educ. Week, 14-15. http://www.edweek.org/ew/articles/1999/02/03/21n peat.h18.html?tkn=PPUF\%2FKgdZ\%2BwmkYLW U3TvorE7J7B8EcXBTAQJ

Bradley, A., 1999b. As NPEAT's focus shifts, its director resigns. Educ. Week, 18: 7. http://www.edweek.org/ew/articles/1999/06/16/40n peat.h18.html

Plous, S., 1993. The Psychology of Judgment and Decision Making. 1st Edn., McGraw-Hill, New York, USA., ISBN: 10: 0070504776, pp: 352. 